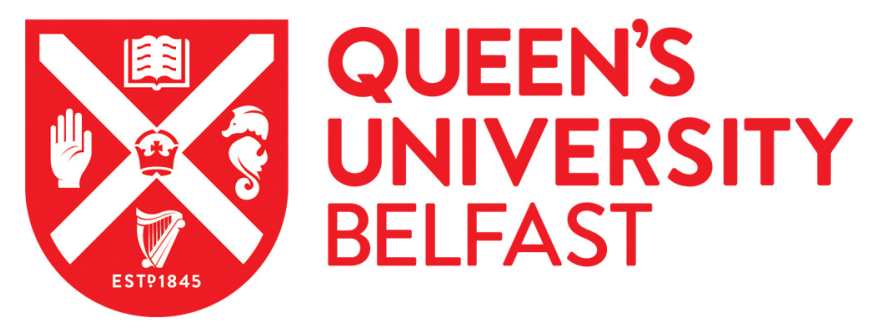

\title{
The scaphopod foot is ventral: more evidence from the anatomy of Rhabdus rectius (Carpenter, 1864) (Dentaliida: Rhabdidae)
}

Sigwart, J. D., Sumner-Rooney, L., Dickey, J., \& Carey, N. (2016). The scaphopod foot is ventral: more evidence from the anatomy of Rhabdus rectius (Carpenter, 1864) (Dentaliida: Rhabdidae). Molluscan Research, 37(2), 79-87. https://doi.org/10.1080/13235818.2016.1257970

Published in:

Molluscan Research

Document Version:

Peer reviewed version

Queen's University Belfast - Research Portal:

Link to publication record in Queen's University Belfast Research Portal

Publisher rights

(C) 2016 The Malacological Society of Australasia and the Society for the Study of Molluscan Diversity

This work is made available online in accordance with the publisher's policies. Please refer to any applicable terms of use of the publisher.

\section{General rights}

Copyright for the publications made accessible via the Queen's University Belfast Research Portal is retained by the author(s) and / or other copyright owners and it is a condition of accessing these publications that users recognise and abide by the legal requirements associated with these rights.

Take down policy

The Research Portal is Queen's institutional repository that provides access to Queen's research output. Every effort has been made to ensure that content in the Research Portal does not infringe any person's rights, or applicable UK laws. If you discover content in the Research Portal that you believe breaches copyright or violates any law, please contact openaccess@qub.ac.uk. 


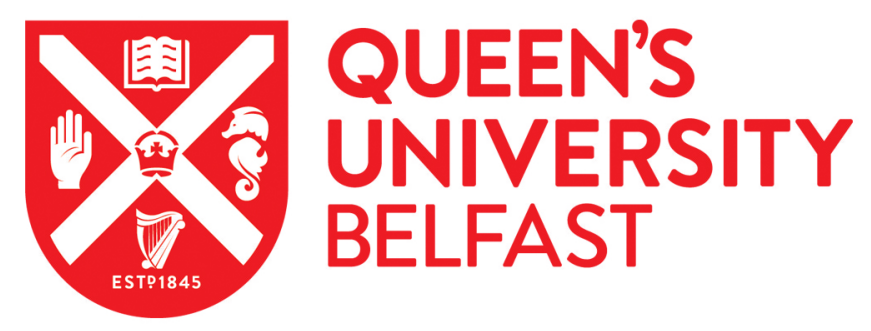

\section{The scaphopod foot is ventral: more evidence from the anatomy of Rhabdus rectius (Carpenter, 1864) (Dentaliida: Rhabdidae)}

Sigwart, J. D., Sumner-Rooney, L., Dickey, J., \& Carey, N. (2016). The scaphopod foot is ventral: more evidence from the anatomy of Rhabdus rectius (Carpenter, 1864) (Dentaliida: Rhabdidae). Molluscan Research, 37(2), 79-87. https://doi.org/10.1080/13235818.2016.1257970

\section{Published in:}

Molluscan Research

\section{Document Version:}

Peer reviewed version

Queen's University Belfast - Research Portal:

Link to publication record in Queen's University Belfast Research Portal

Publisher rights

(C) 2016 The Malacological Society of Australasia and the Society for the Study of Molluscan Diversity

This work is made available online in accordance with the publisher's policies. Please refer to any applicable terms of use of the publisher.

\section{General rights}

Copyright for the publications made accessible via the Queen's University Belfast Research Portal is retained by the author(s) and / or other copyright owners and it is a condition of accessing these publications that users recognise and abide by the legal requirements associated with these rights.

Take down policy

The Research Portal is Queen's institutional repository that provides access to Queen's research output. Every effort has been made to ensure that content in the Research Portal does not infringe any person's rights, or applicable UK laws. If you discover content in the Research Portal that you believe breaches copyright or violates any law, please contact openaccess@qub.ac.uk. 


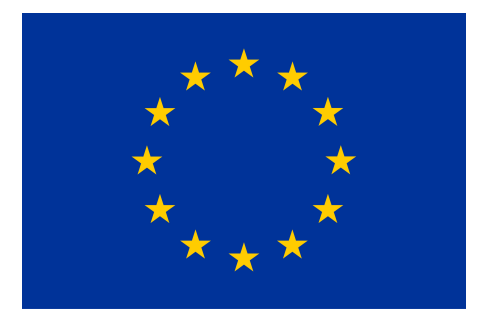

This project has received funding from the European Union's Horizon 2020 research and innovation programme under the Marie Skłodowska-Curie grant agreement No H2020-MSCAIF-2014-655661.

This copy of the accepted manuscript is provided to enable dissemination through Open Access to the scientific data; the version of record is that provided by the publishers. 
The scaphopod foot is ventral: more evidence from the anatomy of Rhabdus rectius (Carpenter, 1864) (Dentaliida: Rhabdidae)

Julia D. Sigwart ${ }^{1,2, *}$, Lauren H. Sumner-Rooney ${ }^{1,3}$, James Dickey ${ }^{1}$, Nicholas Carey ${ }^{4}$

1. Queen's University Belfast, Marine Laboratory, 12-13 The Strand, Portaferry, N. Ireland: j.sigwart@qub.ac.uk, lsumnerrooney01@qub.ac.uk, jdickey03@qub.ac.uk tel. +44 (0)28 42727804

2. University of California, Berkeley, Museum of Paleontology, 1101 Valley Life Science Building, Berkeley, USA

3. Museum für Naturkunde, Invalidenstraße 43, 10115 Berlin, Germany

4. Hopkins Marine Station, Stanford University, Pacific Grove, California, USA:

ncarey@stanford.edu

* corresponding author

Running head: The scaphopod foot is ventral

Keywords: Mollusca; Scaphopoda; tusk shells; homology; sexual dimorphism; body axes; dorso-ventral musculature; AMIRA; tomographic model 


\begin{abstract}
Scaphopods comprise about 900 described species of elongate infaunal molluscs, separated into two orders. The phylogenetic position of this class is contentious, having been proposed as a sister-group to bivalves or alternatively cephalopods, all groups that notably represent dramatic modifications of the molluscan body plan and historical confusion over the fundamental body axes. The digging scaphopod foot was previously considered to be anterior. Here we use a three-dimensional tomographic reconstruction of digestive anatomy and partial dorso-ventral musculature, to test the hypothesis that the scaphopod foot is ventral. Similar to cephalopods, the body orientation is confounded by ano-pedal flexion, but rationalising scaphopods is perhaps further undermined by their infaunal lifestyle, which confounds comparison of ecological life position. Some scaphopods are locally abundant, providing good quality material for anatomical study. In our focal species, Rhabdus rectius (Carpenter, 1864), sexes can reliably be differentiated in vivo by differential colour of the gonad (yellow in females; white in males). The gut is composed of three complete loops. Based on the orientation of the digestive tract and the dorso-ventral muscles, we find further evidence to support the interpretation that the concave side of the scaphopod shell is anterior (the site of the mouth) and the foot is ventral.
\end{abstract}

\title{
Introduction
}

Scaphopods are a relatively under-studied and enigmatic class of molluscs. They live infaunally, burrowing into seafloor sediment. Their distinctive curved, tapered shell has both a narrow aperture, which often projects above the sediment surface, and a broader aperture, from which the foot and anchoring organ emerge and dig into the sediment. Scaphopods are ecologically important benthic infaunal predators, with many species feeding primarily on foraminifera (Fischer-Piette and Franc 1969; Bilyard 1974; Shimek 1990; Langer et al. 1995). The scaphopod captures its prey using numerous feeding tentacles called captacula, frequently from within a 'feeding cavity' excavated by the foot in the sediment around the larger shell aperture (Gainey 1972; Bilyard 1974).

As with many members of infaunal communities, the fact that scaphopods live out of sight can limit biological observations, and hence our relatively sparse knowledge of their biology compared to some of the other molluscan classes. However, even cryptic infaunal species such as scaphopods are nonetheless important to ocean biogeochemistry and carbon cycling (Gooday et al. 1992), and burrowing marine animals may be particularly sensitive to changes in sediment composition and human disturbance (Green et al. 2016). Occupation of these 
habitats clearly prompts some morphological evolution, including adaptations in the form of digging and anchoring structures. Such adaptations are seen in bivalves and scaphopods, and also in members of other phyla such as sipunculids and enteropneusts. But an awareness of these specific adaptations alone is not sufficient when faced with diverse and unusual communities, and scaphopods are among those taxa that merit further attention.

The anatomy and biology of scaphopods has been described in detail for several species (e.g. Lacaze-Duthiers 1856; Plate 1892; Fischer-Piette and Franc 1969). However, assumptions about the uniformity of the class may have limited the progress of studies which use a detailed comparative approach (Steiner 1994), and a proportion of observations and studies remain unpublished (e.g. unpublished theses: Herbert 1986; Davies 1987). The class is clearly divided into two major orders, Dentaliida and Gadilida, consistently supported by both molecular phylogenetic results and substantial anatomical differences (Steiner 1998; Stöger et al. 2013). Beyond this, comparisons of anatomical features are less common, but where more comprehensive comparative studies exist they do demonstrate interesting variability (e.g. Steiner 1992, 1994).

The placement of this class in a framework of molluscan phylogeny remains singularly contentious (e.g., Smith et al. 2013; Sigwart and Lindberg 2015). Bivalves are one putative sister group to scaphopods (Runnegar and Pojeta 1974); however most similarities seem to be convergent to an infaunal lifestyle (Waller 1998; Wanninger and Haszprunar 2002). Recent neuroanatomical comparisons and gene expression evidence have both indicated a closer relationship between scaphopods and cephalopods (Sumner-Rooney et al. 2015; Wollesen et al. 2015). In order to understand the evolutionary history of scaphopods, it is important to understand the basic homology of key characters between these and other molluscs outside the class.

The scaphopod body plan is so dramatically modified compared to other molluscs that even basic comparisons are challenging (Sumner-Rooney et al. 2015). The absence of key organ systems, such as ctenidia and heart, confounds anatomical comparisons to other molluscs (Reynolds 2002). Confusion exists even over the fundamental anatomical axes of the body (Dinamani 1964; Wanninger and Haszprunar 2001; Sumner-Rooney et al. 2015). Visualisations of anatomy using three-dimensional modelling provide the ability to see organ systems in situ within the intact context of the body. This technique allows for new insights that are not possible through conventional dissection (Chen et al. 2015). Here we used digital tomography to examine the organ systems in a scaphopod, to describe some details of the anatomy of Rhabdus rectius (Carpenter, 1864) specifically, and to clarify positional 
homologies for scaphopods in general. Rhabdus exhibits some apparently unique features, such as sensory slits in the mantle (Steiner 1991; Sumner-Rooney et al. 2015), so its anatomy is particularly interesting for future comparisons with other scaphopods. The present study serves to summarise some basic information about scaphopod gross anatomy and particularly the interpretation of body axes, and to show how these specifically manifest in Rhabdus rectius.

\section{Materials and Methods}

These data are drawn from specimens from a combination of fieldwork by the authors, and museum specimens in the collection of the California Academy of Sciences (CAS-IZ). All specimens were collected by dredging in Barkley Sound (Imperial Eagle Channel, 4853.72’ N, 12509.78'W, ca. 90 m depth, collected in 1988, 2011, 2013), Vancouver Island, near the Bamfield Marine Sciences Centre, British Columbia, Canada.

We reconstructed a three-dimensional tomographic model of the digestive system of Rhabdus rectius from serial sections of a small adult individual ( $13 \mathrm{~mm}$ specimen length). The specimen was relaxed and fixed by adding $\mathrm{MgCl}_{2}$ dropwise to a watch glass of chilled seawater until the animal became unresponsive; at that point, $10 \%$ buffered formalin was added dropwise to the bath until the volume had been completely replaced. The fixed specimen was subsequently decalcified in EDTA, post-fixed in 1\% osmium tetroxide, dehydrated in an acetone series and embedded in Epon epoxy resin for serial sectioning. Digital images of semi-thin sections ( $1.5 \mu \mathrm{m}$ thick), subsampled at 1 in each 15 sections from the series, were aligned and tissues identified and labelled in AMIRA (FEI). Histology and tomography follow the methods of Ruthensteiner (2008); for a detailed account see SumnerRooney et al. (2015) who undertook earlier work on this same specimen.

Because of the body plan in scaphopods, this sectioning project resulted in a very large number (> 8000) of sections deposited at the Zoologische Staatssammlung München (ZSM). The first part of the body was used to complete a previously-published model of the central nervous system (Sumner-Rooney et al. 2015). The present results come from the examination of a second set of sections from the same specimen, which allowed us to detail the digestive system, dorsal nerves, and the anatomy of some major muscle groups. The dorsal-most aspect, composed primarily of gonad, was not used for tomographic reconstruction.

\section{Results}




\section{$<$ FIGURES $1 \& 2$ ABOUT HERE $>$}

Observations herein are documented following the body axes as determined by SumnerRooney et al. (2015; Figures 1, 2), an issue which is discussed in more detail below.

The lateral nerves connect the pleural ganglia at the dorsal aspect of the oesophageal nerve ring (Sumner-Rooney et al. 2015), to the visceral ganglia. We interpret the visceral ganglia as such because of their position in relation to the anus (Figure 3). We were unable to trace nerve cords any further dorsally beyond the visceral ganglia. Previous descriptions of the scaphopod nervous system in other species could not identify specific nerves in this body region; these nerves must exist, yet they have not specifically been described, and have been routinely illustrated schematically as dotted lines (Lacaze-Duthiers 1856; Fischer-Piette and Franc 1969). Although they have not been observed, nerves do extend from the dorsal corner of each visceral ganglion and these probably do connect the visceral ganglia with the nerve ring in the tissue of the pavilion at the dorsal (narrow) shell aperture (Wanninger and Haszprunar 2003).

The radula and buccal apparatus are large and muscular, and the buccal cartilages are entirely enclosed within a dense buccal muscle block (Figures $1 \mathrm{~F}, 3,4$ ). There is a thick cuticle underlying the radula on the surface of the buccal muscle block (Figure 4B). The pharynx, including the buccal pouch, is very broad and expands posteriorly behind the buccal muscles. The pharynx tapers dorsally to the foregut, the thinner aspect of the digestive tract that leads vertically to the stomach at the dorsal extreme of the digestive loop. The stomach lumen diverges into two large and distinct digestive diverticula which are interconnected with the digestive gland. The digestive gland is large, bilaterally symmetrical and extends in a large mass both ventrally and mostly dorsally of the apex of the gut coiling (Figure 3A; note that the whole digestive gland was not reconstructed and it is dorsally truncated). The digestive gland is visible through the transparent shell in vivo as a dark brown to black mass immediately ventral to the gonad (Figure 1E).

Beyond the digestive diverticula, the posterior intestine doubles back sharply in a hairpin turn and runs in parallel with the foregut, as far ventral as the pharynx (Figure 3A). The gut coils into three complete posterior loops (the fourth half-loop terminates at the anus), concentrated ventrally. After the first return ventrally from the stomach and digestive diverticula (section 2, Figure $3 \mathrm{~B}$ ), the intestine makes another $180^{\circ}$ turn, ascends dorsally in the middle of the gut coil (section 3, not visible in Figure 3B), then follows another $180^{\circ}$ turn to return ventrally to the base of the pharynx, posterior and ventral to section 2, then makes another complete loop 
(sections 5-6) posterior to the preceding gut. Accordingly, there are seven tightly-packed intestinal sections visible in cross section (numbered sequentially in Figure 3B; Figure 4). After a final $180^{\circ}$ turn to run dorsally at the right of the intestinal coil (section 7), the gut turns posteriorly to meet the body wall at the anus, immediately dorsal of the visceral ganglia. The sections running dorsally are odd numbers, and are generally on the left body side (upwards in Figure 1, Figure 3, cf. Figure 4); this is the same arrangement as reported by Steiner (1994) in several other species.

\section{$<$ FIGURES 3 \& 4 ABOUT HERE $>$}

The dorso-ventral musculature connects ventrally to a large muscular collar at the mantle margin (Figure 3C). In Rhabdus rectius there are distinct bands of dorso-ventral muscles, in two pairs of equal vertical bands on either side of the pharynx. To the left and right each pair conjoins to form a single muscle band at approximately the midpoint of the intestinal coil mass (Figure 3C). These remaining two muscles then traverse to the body anterior and fuse into a single sheet that forms a thin line on the shell anterior face for the rest of the length of the body, which is mainly occupied by the gonad (Figure 1A).

Herein, we confirmed that the gonad in male Rhabdus rectius is white, and the female ovary is yellow (Figures 1A, 1E). Examination of several hundred individuals confirmed that there is no apparent intermediate gradation in colouration; however, colour may be occasionally obscured by the opacity of the shell or by white plaques on the shell surface. In some individuals, the differential texture of ova and testes is also visible even through the shell.

\section{Discussion}

Anatomy of Rhabdus rectius

The general anatomy of scaphopods has been well described over a long history of research (Lacaze-Duthiers 1856; Plate 1892; Fischer-Piette and Franc 1969), though detailed studies have consistently revealed species-level differences (Shimek 1988; Steiner 1992, 1994). The digestive system of dentaliid scaphopods varies among species in relative length, coiling, and complexity, and this is probably related to diet (Steiner 1994). Scaphopod species have distinct dietary compositions and preferred prey (Shimek 1990). The gut in Rhabdus rectius follows the same basic arrangement as described in other species of scaphopods, but represents a coiling pattern (described above) that is potentially distinctive to the species. 
Scaphopods possess unusual filamentous tentacular sensory extensions called captacula, which are used for feeding and exploration. The histology and species-specific anatomy of captacula have been described in some detail, including for Rhabdus rectius (e.g. FischerPiette and Franc 1969; Shimek 1988). These filaments are elastic, each terminating in a single ganglion, and the ciliated captacular head grips prey items to return them to the mouth (Yonge 1937; Morton 1959; Shimek and Steiner 1997). The captacular mass can be entirely retracted within the mantle cavity. When the foot is withdrawn, individual captacula may be used to explore the animal's immediate surroundings (Figure 1B). Scaphopods shed captacula readily (this is apparently exacerbated when they are under stress in lab conditions), and presumably also regenerate and grow new captacula continuously. Early descriptions suggested that shorter and longer captacula may represent anatomically different forms (Plate 1892), but they are all anatomically equivalent and in different stages of growth (FischerPiette and Franc 1969); however, shorter and longer captacula may play different roles in feeding activities (Taib 1980). We did not attempt to trace any individual captacula, or assess their lengths, but note that the natural intact mass of captacula in Rhabdus rectius occupies a very large volume in the mantle groove (Figure 1D, Figure 4).

The pedal musculature of scaphopods is complex, representing multiple concentric muscle layers (Plate 1892), and was described in a comparative context from many species by Steiner (Steiner 1992). We have not reconstructed the pedal musculature in the present material, as the current study focused on the dorsal region above the foot complex. The banding of the dorso-ventral muscles in the abdominal region varies among different families, and the separation into two equal pairs of bands as confirmed here is a character shared by the families Rhabdidae, Dentaliidae, and Laevidentaliidae (Steiner 1998).

\section{Sexual dimorphism}

The largest portion of the adult scaphopod body is occupied by the gonad (Figures 1A, 1E). Male and female gonads can be distinguished in vivo by colour, though the colour of the gonads varies among species (McFadien-Carter 1979; Lamprell and Healy 1998). Yet the reproductive biology of scaphopods is poorly known, with little information on seasonality, gametogenesis or spawning (Buckland-Nicks et al. 2002). The sexes are separate, and as in most molluscs, the gonad is inferred to wax and wane in size; the ripe gametes are enclosed by a transparent membrane (Lacaze-Duthiers 1856). In species like Rhabdus rectius with a semi-transparent shell, the gonad is visible in vivo (Figure 1E). As well as other scaphopod species in the eastern Pacific, adults of Rhabdus rectius apparently have at least some mature gametes present at all times (Rokop 1977; Herbert 1986). Gonad colour can be used as a 
secondary sexual characteristic, and thus individuals can be sexed without dissection or histology (McFadien-Carter 1979, Herbert 1986).

Previous data from other scaphopod species in Australia suggested that female individuals were generally larger than males (Lamprell and Healy 1998). Surprisingly, Rhabdus rectius demonstrates opposite sexual dimorphism, with male individuals being on average larger than females by dry weight. In Dentalium neohexagonum Sharp \& Pilsbry in Pilsbry \& Sharp, 1897 the ventral aperture morphology varies with gender (McFadien-Carter 1979). Among dentaliid scaphopods there is therefore apparently a surprising range of dimorphism. Males and females are easily distinguishable; however, characters such as body size, morphology, and metabolic rate may vary in opposite ways in different species.

\section{Scaphopod body axes}

Tomographic anatomical models provide an interactive visualisation of the major organ systems, and can offer novel insights compared to traditional dissection. Detailed anatomical studies have been published for at least twenty species of scaphopods; however, perhaps because of early assumptions about homogeneity in the class, many early authors did not document species identifications for the material they described (Sigwart and Sumner-Rooney 2015). The organisation of the body in Rhabdus rectius follows previous descriptions of dentaliid scaphopods (Shimek and Steiner 1997). Three-dimensional visualisation of the organs in situ clarifies the generalised positional homologies within the highly modified scaphopod body in the wider context of the molluscan bauplan.

In most bilaterally symmetrical animals, the mouth is anterior and the anus is posterior, and in molluscs, the shell is dorsal and the foot is ventral. Phylum Mollusca encompasses a famously disparate range of body plans, but in most cases body orientation is straightforward, though there is enduring controversy about cephalopods (Shigeno et al. 2008) as well as scaphopods. Establishing homologies among all eight living classes of molluscs is highly important to progress the resolution of pan-molluscan phylogeny (Sigwart and Lindberg 2015). For example, the body axes of bivalves are not contentious and offer a useful comparison for the interpretation of major character sets in other highly modified body plans. In bivalves, the foot emerges ventrally between the two shell valves, and the dorso-ventral muscles attach the foot to the shell toward the dorsal hinge; the foregut is at the anterior aspect, and the anus empties posteriorly, often into the exhalant siphon. This is anatomically intuitive, but can be difficult to recognise in vivo as the direction of the gut is not always obvious and life positions of bivalves vary considerably among taxa. 
In scaphopods, the foot emerges from the larger shell aperture, the mouth is positioned adjacent to the foot under the concave face of the dorso-ventrally elongate shell, and the anus is positioned toward the convex side (Figure 1). In much prior literature, the foot was described as anterior, and the convex side was considered ventral (the orientations noted 'formerly' in Figure 2). Standard textbooks and reference works follow this 'anterior-foot' orientation (e.g. Hayward and Ryland 1995) or avoid discussion of scaphopod body axes altogether (e.g., Pechenik 2005). Sumner-Rooney et al. (2015) described the central nervous system architecture in Rhabdus rectius, and used homologies with other examples of molluscan tetraneury and positional relationships, to determine that the body axes should be interpreted with the foot in ventral position. New evidence here from gross anatomy supports that conclusion.

The recently proposed new interpretation of the foot as ventral and the shell apex as dorsal was based primarily on the configuration of the oesophageal nerve ring (Sumner-Rooney et al. 2015). The basic elements of tetraneury are intact in scaphopods (an oesophageal nerve ring emitting two pairs of nerves that innervate the foot and the viscera), but the oesophageal nerve ring is elongated dorso-ventrally to the point that it is difficult to recognise. In all molluscs, the buccal tube or oesophagus passes through the oesophageal nerve ring on a primarily anterior-posterior body axis (Sigwart and Sumner-Rooney 2015). In Rhabdus rectius, the buccal tube is very elongate, stretched almost parallel to the oesophageal nerve ring, but the passage through the oesophageal nerve ring runs on the shorter body axis (Fig. 1D). Using this and other neural features as a basis for homology, the shorter body axis is interpreted as anterior-posterior, and the shell is dorsal-ventrally elongate, with the foot emerging from the ventral aperture.

Here, we consider the evidence from two additional systems that can be compared with homologies in other molluscan classes: dorso-ventral musculature, and the digestive anatomy (Figure 2, Figure 3). While the positions of dorso-ventral muscles and the digestive loop could be considered logically consistent with the traditional approach of an anterior foot, they cannot provide any evidence against the interpretation of the scaphopod foot as ventral. Interpreting the scaphopod foot as ventral appears to be the more parsimonious arrangement.

This interpretation of the scaphopod body can be visualised as compared to a very tall keyhole limpet, with a dorsal opening, a ventral foot, and antero-ventrally directed mouth. Scaphopods are not torted, thus their anus is directed posteriorly. Many fissurellid limpets also primarily grow their shell downward at the ventral margin, but maintain a dorsal 
aperture. (To further the analogy, scaphopods also emit their gametes through the dorsal aperture; Reynolds 2002.) The shells of modern scaphopod species are composed of aragonite and are often thin and fragile (Reynolds and Steiner 2008). Accretionary growth occurs mainly at the ventral margin, but the animals control shell calcification at both dorsal and ventral apertures (Shimek and Steiner 1997; Reynolds 2002). Scaphopods must decalcify the dorsal aperture to enlarge it as the body grows larger. They can also recalcify, and some species grow a secondary shell or 'pipe' that emerges as an extension of the proximal shell layer at the dorsal aperture (e.g., Lamprell and Healy 1998).

The dorso-ventral muscles traverse the long axis of the scaphopod body (Figure 2) from their attachment to a muscle ring at the ventral mantle margin near the foot, leading into the narrower part of the body (Steiner 1998), and these muscles run from the convex side to the concave side of the shell (from bottom left to top right in the schematic in Figure 2). The dorso-ventral muscles thus cross the body diagonally, meaning that either the long axis (top to bottom in Figure 2) or the short axis (left to right) could potentially be considered the dorsoventral axis. Diagonally intercrossing dorso-ventral muscles are also found in most other molluscan groups, connecting to the ventral foot (Haszprunar and Wanninger 2000). Here, we interpret the long axis to be dorso-ventral (i.e., from top to bottom in Figure 2), following the major extension of the dorso-ventral musculature.

The digestive system is constrained by the narrowly enclosed scaphopod shell; both mouth and anus oriented toward the larger shell aperture that is normally submerged in the sediment. The U-shaped gut has been compared to the arrangement in cephalopods and gastropods, both groups that have a turn in the digestive tract caused by ano-pedal flexion, such that the anus returns forward (Wanninger and Haszprunar 2002; Sumner-Rooney et al. 2015). This is a trait that unifies scaphopods with cephalopods and gastropods (Ponder and Lindberg 1997; Lindgren et al. 2004). In scaphopods the anus is above the mouth, although it is directed ventrally (cf. Figure 2; Reynolds 2002). In torted gastropods, mouth and anus both are located toward the anterior body aspect, and previous descriptions of scaphopods transpose this interpretation as jointly anterior on to the shell opening closer to the scaphopod mouth and anus. Our tomographic reconstruction of the digestive system (Figure 1, Figure 3) clarifies that the mouth and anus are in fact on opposite sides of the body (left and right in Figure 2). Although there is species-specific variation in the digestive anatomy, the relative positions of the mouth and anus remain consistent (Steiner 1994). This supports our proposed interpretation of an anterior mouth and posterior anus. 
Our interpretations here are based on the adult body axes, but this is also applicable to early ontogeny. In larval development, scaphopods experience a gradual metamorphosis from trochophore to veliger to early juvenile stages. The early stage veligers have an anterior apical tuft and a posterior anus, a dorsal shell field and ventral foot (Lacaze-Duthiers 1856; McFadien-Carter 1979; Wanninger and Haszprunar 2002). The anus later migrates anteriorly, folding the body viscera in the process of ano-pedal flexion (see also Peel 2006). In late larval stages where the shell is relatively short, the dorso-ventral extension of the main muscles is much clearer than in later, hyper-elongated adult scaphopods (Wanninger and Haszprunar 2002). Thus, in all life stages, the foot and mouth remain as the defining extremities of the ventral and anterior body directions.

Previous literature on scaphopods provides a basis for understanding the consistent anatomical arrangement of the dorso-ventral musculature and digestive tract in a generalised scaphopod body plan. Specific descriptions, such as our data presented here, are essential to reconstruct finer-level phylogenetic relationships and in understanding the ecological adaptations of these species. At a much broader level, beyond the taxonomic class, clear homologies with the body architecture of other molluscs will enable comparisons across the entire phylum and critical interpretation of the expansive molluscan fossil record. This change in interpretation of body axes is a departure from most reference works, but it clarifies scaphopod anatomy. The anterior-posterior body axis in scaphopods corresponds to the position of the mouth and the anus, and the oesophagus passes through the oesophageal nerve ring from posterior to anterior as in all other molluscs. And, in scaphopods as in all other molluscan classes, the foot is ventral.

\section{Acknowledgements}

We are very grateful to Eva Lodde-Bensch (ZSM, Munich) who completed the histological sectioning. Our particular thanks also go to Ron Shimek for sharing his insights of the biology of Rhabdus rectius. We also thank Michael Schrödl (ZSM), Terry Gosliner (California Academy of Sciences), and the staff of the Bamfield Marine Sciences Centre, including the skipper and crew of the M/V Alta. We are indebted to David Lindberg and John Pearse for their constructive reviews that improved an earlier version of this manuscript. This work was supported by the European Commission (award H2020-MSCA-IF-2014-655661 to JDS). 


\section{References}

Bilyard, G.R. (1974) The feeding habits and ecology of Dentalium entale stimpsoni Henderson. The Veliger 17, 126-138.

Buckland-Nicks, J., Gibson, G., \& Koss, R. (2002) Phylum Mollusca: Polyplacophora, Aplacophora, Scaphopoda. In: Young, C.M. (Ed.), Atlas of Marine Invertebrate Larvae. Academic Press Inc., San Diego, USA, pp. 245-256.

Chen, C., Copley, J.T., Linse, K., Rogers, A.D., \& Sigwart, J.D. (2015) The heart of a dragon: 3D anatomical reconstruction of the "scaly-foot gastropod" (Mollusca: Gastropoda: Neomphalina) reveals its extraordinary circulatory system. Frontiers in Zoology 12, 13. DOI: $10.1186 /$ s12983-015-0105-1

Davies, G.R. (1987) Aspects of the biology and ecology of deep sea scaphopods. PhD Thesis. Heriot Watt University.

Dinamani, P. (1964) Burrowing behaviour of Dentalium. Biological Bulletin 126, $28-32$.

Fischer-Piette, E.\& Franc, A. (1969) Classe des scaphopodes. In Grasse, P.-P. (Ed.), Traité de Zoologie, Mollusques, Gastéropodes et Scaphopodes. Mason et Cie, Paris, France. pp. 987-1017

Gainey, L. F. (1972) The use of the foot and the captacula in the feeding of Dentalium (Mollusca: Scaphopoda). The Veliger 15, 29-34.

Gooday, A.J., Levin, L.A., Linke, P. \& Heeger, T. (1992) The role of benthic foraminifera in deep-sea food webs and carbon cycling. In: Rowe, G.T. \& Parente, V. (Eds.), Deep-Sea Food Chains and the Global Carbon Cycle. Kluwer Academic Publishers, Dordecht. pp. 63-91.

Green, D.S., Boots, B., Sigwart, J.D., Jiang, S., \& Rocha, C. (2016) Effects of conventional and biodegradable microplastics on a marine ecosystem engineer and nutrient cycling. Environmental Pollution Bulletin 208B, 426-434

Haszprunar, G. \& Wanninger, A. (2000) Molluscan muscle systems in development and evolution. Journal of Zoological Systematics and Evolutionary Research 38, 157-163.

Hayward, P. J. \& Ryland, J. S. (1995) Handbook of the Marine Fauna of North-West Europe. Oxford University Press, Oxford, UK.

Herbert, A. (1986) Reproductive behavior and anatomy of three Central Californian scaphopods. MSc thesis. California State University, Hayward.

Lacaze-Duthiers, H. (1856) Histoire de l'organisation et développement du Dentale. Annales des Sciences Naturelles Quatrième Series Tome 6, 225-281.

Lamprell, K.L. \& Healy, J.M. (1998) A revision of the Scaphopoda from Australian waters (Mollusca). Records of the Australian Museum Supplement 24, 1-189.

Langer, M.R., Lipps, J.H., \& Moreno, G. (1995) Predation on foraminifera by the dentaliid deep-sea scaphopod Fissidentalium megathyris. Deep-sea Research I 42, 849-857.

Lindgren, A.R., Giribet, G., \& Nishiguchi, M.K. (2004) A combined approach to the phylogeny of Cephalopoda (Mollusca). Cladistics 20, 454-486.

McFadien-Carter, M. (1979) Scaphopoda. In: Giese, A.C. \& Pearse, J.S. (Eds.), Reproduction of Marine Invertebrates. Molluscs: Pelecypods and Lesser Classes. Vol. 5. Academic Press, New York, USA. pp. 95-111

Morton, J.E. (1959) The habits and feeding organs of Dentalium entalis. Journal of the Marine Biological Association 38, 225-238.

Pechenik, J.A. (2005). Biology of the Invertebrates: 5th Edition. McGraw-Hill, New York, USA.

Peel, J.S. (2006). Scaphopodization in Palaeozoic molluscs. Palaeontology, 49(6), 1357-1364.

Plate, L.H. (1892). Über den Bau und die Verwandtschaftsbeziehungen der Solenoconchen. Zoologische Jahrbücher. Abteilung fur Anatomie und Ontogenie der Tiere, 5, 301-386.

Ponder, W.F. \& Lindberg, D.R. (1997) Towards a phylogeny of gastropod molluscs: an analysis using morphological characters. Zoological Journal of the Linnean Society 1(19), 83-265.

Reynolds, P.D. (2002) The Scaphopoda. Advances in Marine Biology 42, 137-236. 
Reynolds, P.D. \& Steiner, G. (2008) Scaphopoda. In: Phylogeny and Evolution of the Mollusca. Ponder, W.F. \& Lindberg, D.R. (Eds.), University of California Press, Berkeley, USA. pp. 143-161.

Rokop, F. J. (1977) Seasonal reproduction of the brachiopod Frieleia halli and the scaphopod Cadulus californicus in the deep sea. Marine Biology 43, 237-246.

Runnegar, B. \& Pojeta, J. (1974) Molluscan phylogeny: the paleontological viewpoint. Science 186, 311-317.

Ruthensteiner, B. (2008) Soft part 3D visualisation by serial sectioning and computer reconstruction. Zoosymposia 1, 63-100.

Shigeno, S., Sasaki, T., Moritaki, T., Kasugai, T., Vecchione, M. \& Agata, K. (2008) Evolution of the cephalopod head complex by assembly of multiple molluscan body parts: Evidence from Nautilus embryonic development. Journal of Morphology 269, 117.

Shimek, R. L. (1988) The functional morphology of scaphopod captacula. The Veliger 30, 213-221.

Shimek, R. L. (1990) Diet and habitat utilization in a Northeastern Pacific Ocean scaphopod assemblage. American Malacological Bulletin 7, 147-169.

Shimek, R.L. \& Steiner, G. (1997) Scaphopoda. In: Harisson, F.W. \& Kohn, A.J. (Eds.), Microscopic Anatomy of Invertebrates, Volume 6B, Mollusca II. Wiley-Liss, New York, USA. pp. 719-781.

Sigwart, J.D. \& Lindberg, D.R. (2015) Consensus and confusion in Molluscan trees: evaluating morphological and molecular phylogenies. Systematic Biology 64, 384-395.

Sigwart, J.D. \& Sumner-Rooney, L.H. (2015) Mollusca: Caudofoveata, Monoplacophora, Polyplacophora, Scaphopoda, Solenogastres. In: Schmidt-Rhaesa, A., Harzsch, S., \& Purschke, G. (Eds.), Structure and Evolution of Invertebrate Nervous Systems. Oxford University Press, Oxford, UK.

Smith, S.A., Wilson, N.G., Goetz, F.E., Feehery, C., Andrade, S.C.S., Rouse, G.W., Giribet, G. \& Dunn, C.W. (2013) Corrigendum: resolving the evolutionary relationships of molluscs with phylogenomic tools. Nature 493, 708-708.

Steiner, G. (1991) Observations on the anatomy of the scaphopod mantle and the description of a new family, the Fustiariidae. American Malacological Bulletin 9, 1-20.

Steiner, G. (1992) The organisation of the pedal musculature and its connection to the dorsoventral musculature in Scaphopoda. Journal of Molluscan Studies 58, 181-197.

Steiner, G. (1994) Variations in the number of intestinal loops in Scaphopoda (Mollusca). Marine Ecology 15, 165-174.

Steiner, G. (1998) Phylogeny of Scaphopoda (Mollusca) in the light of new anatomical data on the Gadilinidae and some Problematica, and a reply to Reynolds. Zoologica Scripta 27, 73-82.

Stöger, I., Sigwart, J.D., Kano, Y., Knebelsberger, T., Marshall, B.A., Schwabe, E. \& Schrödl, M. (2013) The continuing debate on deep molluscan phylogeny: evidence for Serialia (Mollusca, Monoplacophora + Polyplacophora). Biomed Research International Article ID 407072. doi: 10.1155/(2013/407072

Sumner-Rooney, L. H., Schrödl, M., Lodde-Bensch, E., Lindberg, D. R., Heß, M., Brennan, G.P. \& Sigwart, J.D. (2015) A neurophylogenetic approach provides new insight to the evolution of Scaphopoda. Evolution and Development 17, 337-346.

Taib, N. T. (1980) Some observations on living animals of Dentalium entalis L. Journal of the College of Sciences, University of Riyadh 11, 129-144.

Waller, T. R. (1998) Origin of the molluscan class Bivalvia and a phylogeny of major groups. In: Johnston, P.A. \& Haggart, J.W. (Eds.), Bivalves - an Eon of Evolution. University of Calgary Press, Calgary, Canada. pp. 1-45 .

Wanninger, A. \& Haszprunar, G. (2001) The expression of an engrailed protein during embryonic shell formation of the tusk-shell, Antalis entalis (Mollusca, Scaphopoda). Evolution and Development 3, 312-21. 
Wanninger, A. \& Haszprunar, G. (2002) Muscle development in Antalis entalis (Mollusca, Scaphopoda) and its significance for scaphopod relationships. Journal of Morphology 254, 53-64.

Wanninger, A. \& Haszprunar, G. (2003) The development of the serotonergic and FMRFamidergic nervous system in Antalis entalis (Mollusca, Scaphopoda). Zoomorphology 122, 77-85.

Wollesen, T., Rodríguez Monje, S. V., McDougall, S. V., Degnan, B. M. \& Wanninger, A. (2015) The ParaHox gene Gsx patterns the apical organ and central nervous system but not the foregut in scaphopod and cephalopod mollusks. Evodevo 6, 41. doi: 10.1186/s13227-015-0037-z

Yonge, C. M. (1937) Circulation of water in the mantle cavity of Dentalium entalis. Proceedings of the Malacological Society of London 22, 333 - 338 


\section{Figure captions}

Figure 1. Anatomy of Rhabdus rectius. In all parts, anterior is to right, dorsal is at top. A. Gonad, showing texture and colour differences in ovary (yellow, left) and testes (white, right) in a preserved specimen CAS-IZ 75615. B. Foot mostly retracted within the ventral opening, in vivo, with captacula extended. C. Foot partially extended showing anchoring organ, and the mantle slit or Steiner organ. D. Tomographic model of the region shown in B, C, illustrating nervous system, buccal tube and radula (redrawn from Sumner-Rooney et al. 2015). E. Live animals, female (left) and male (right), with boxes indicating regions of interest shown in other parts of this figure. F. Tomographic model of the digestive system showing right side view. Abbreviations: $a n$, anus; $b c$, buccal cartilage, surrounded by buccal musculature (transparent); bt, buccal tube (mouth); ca, captacula, or captacular mass in tomographic models (transparent purple); $c g$, cerebral ganglia; $d d$, digestive diverticula (dorsal outpocketings of stomach); $d g$, digestive gland; $d v m$, dorso-ventral muscles; $e p$, epipodial lobes; $i n$, intestine; $l n$, lateral nerve; $m a$, mantle; $m n$, mantle nerve; $o v$, ovary; $p g$, pedal ganglia; $p h$, pharynx and buccal pouch; plg, pleural ganglia; $p t$, pedal tip; ra, radula; sh, shell; so, Steiner organ; st, stomach; te, testes; vg, visceral ganglion. Colours in tomographic models: black, digestive tract; grey, digestive gland; light teal, buccal cartilage; dark teal, radula; magenta, nervous system; blue, mantle nerves; purple, captacular mass; statocysts are rendered in yellow (not labelled, dorsal to pedal ganglia).

Figure 2. Schematic diagram, not to scale, indicating body axes in a generalised scaphopod as interpreted in this study. Orange bands indicate dorso-ventral musculature as in Rhabdus rectius; grey internal line indicates the path of the gut (with pharynx at anterior and anus at posterior).

Figure 3. Tomographic reconstruction of the digestive system and musculature in Rhabdus rectius. Ventral is at bottom; note the pharynx is interpreted as anterior, and the anus as posterior. Scale bar applies to all parts. Loops of the intestine are numbered sequentially starting with the foregut. A. Body left view of digestive system and major nerve cords. B. Posterior view of digestive system and major nerve cords. C. Posterior view (as in B) including dorso-ventral musculature. D. Body right view of digestive system (including digestive gland, excluded in other parts) and dorso-ventral musculature. Abbreviations: an, anus; $b c$, buccal cartilage, surrounded by $b m$, buccal musculature (transparent); $c a$, captacular mass (transparent purple); $d d$, digestive diverticula (dorsal out-pocketings of stomach); $d g$, digestive gland; $d v m$, dorso-ventral muscles; $e p$, epipodial lobes; in, intestine; ln, lateral nerve; $p h$, pharynx and buccal pouch; plg, pleural ganglia; ra, radula; $r m$, retractor muscle; $s t$, 
stomach; vg, visceral ganglion. Colours in tomographic models: black, digestive tract; grey, digestive gland; orange and yellow, musculature; light teal, buccal cartilage; dark teal, radula; magenta, nervous system; purple, captacular mass.

Figure 4. Example sections showing the digestive system of Rhabdus rectius, shown viewed from the dorsal aspect. A. Section through the middle of the intestinal coil; loops of the intestine are numbered sequentially starting with the foregut. B. Section through the radula, showing buccal apparatus. The chevron indicates the cuticular layer underlying the radula. Abbreviations: $b m$, buccal musculature; $c a$, captacular mass (dots in mantle groove); $d v m$, dorso-ventral muscles; ra, radula. 